\title{
Partisipasi Mahasiswa dalam Kegiatan Ekstrakurikuler di Jurusan Ilmu Sosial Politik Universitas Negeri Padang
}

\author{
Muhammad Arif Yuzanda, Junaidi Indrawadi \\ Prodi Pendidikan Pancasila dan Kewarganegaraan \\ FIS Universitas Negeri Padang \\ E-mail: marifyuzanda@gmail.com
}

\section{ABSTRAK}

Penelitian ini dilatarbelakangi oleh kurangnya kesadaran mahasiswa untuk berpartisipasi dalam kegiatan ekstrakurikuler di jurusan Ilmu Sosial Politik. Setiap diadakan kegiatan, selalu ada mahasiswa yang tidak ikut serta dan tidak peduli dengan kegiatan ekstrakurikuler yang diadakan. Penelitian ini bertujuan untuk mengidentifikasi faktor-faktor penyebab mahasiswa ISP yang kurang berpartisipasi dalam kegiatan ekstrakurikuler jurusan. Penelitian ini adalah penelitian kualitatif yang didukung dengan pendekatan kuantitatif atau disebut juga dengan metode kombinasi (mixed methods). Teknik pengumpulan data menggunakan wawancara dan juga angket. Populasi dalam penelitian ini terdiri dari 509 orang mahasiswa Jurusan ISP Prodi PPKn. Informan ditentukan secara purposive sampling, sedangkan teknik penarikan sampel menggunakan teknik proportionate stratified random sampling dengan jumlah responden 84 orang mahasiswa ISP. Hasil penelitian menunjukkan bahwa kurangnya partisipasi mahasiswa ISP dalam kegiatan ekstrakurikuler jurusan disebabkan oleh berbagai faktor yang berbeda-beda antar mahasiswa. Faktor-faktor yang menyebabkan kurangnya partisipasi mahasiswa ISP dalam kegiatan ekstrakurikuler jurusan yaitu, faktor kesehatan, faktor ekonomi, faktor tugas kuliah, faktor kendala izin orang tua, faktor malas, dan faktor ajakan teman untuk tidak mengikuti kegiatan.

Kata Kunci: partisipasi, mahasiswa, kegiatan ekstrakurikuler

\section{ABSTRACT}

This research is motivated by the lack of awareness of students to participate in extracurricular activities in the Department of Social and Political Sciences. Every time an activity is held, there are always students who don't participate and don't care about the extracurricular activities being held. This study aims to identify the factors that cause ISP students who do not participate in extracurricular activities at the department. This research is a qualitative research supported by a quantitative approach or also known as a combination method (mixed methods). Data collection techniques used interviews and questionnaires. The population in this study consisted of 509 students of the PPKn Study Program ISP. The informants were determined by purposive sampling, while the sampling technique used the proportionate stratified random sampling technique with the number of respondents being 84 ISP students. The results showed that the lack of participation of ISP 
students in extracurricular activities at the department was caused by various factors that varied between students. The factors that cause the lack of participation of ISP students in extracurricular activities of the department are health factors, economic factors, college assignment factors, parental permission constraints, laziness factors, and friend invitation factors not to participate in activities.

\section{Keywords: participation, college student, activities extracurricular}

(C) (D) This work is licensed under the Creative Commons Attribution-ShareAlike 4.0 International License. C2021 by author.

\section{PENDAHULUAN}

Mahasiswa merupakan salah satu komponen civitas akademika yang menuntut ilmu pada pendidikan formal di perguruan tinggi, dimana mahasiswa tidak akan terlepas dari aktivitas belajar dan keharusan mengerjakan tugas-tugas studi, baik yang bersifat akademik maupun non akademik. Kegiatan non akademik yaitu suatu kegiatan kemahasiswaan yang dilaksanakan di dalam maupun di luar kampus tanpa diberi bobot sks, yang dapat meliputi bidang penalaran dan kreativitas, kesejahteraan mahasiswa, kewirausahaan, minat dan bakat, organisasi kemahasiswaan, serta kegiatan ekstrakurikuler.

Salah satu kegiatan atau program yang ada di perguruan tinggi yaitu kegiatan ekstrakurikuler. Berdasarkan Kepmendikbud RI No. 155/U/1998 tentang pedoman umum organisasi kemahasiswaan di perguruan tinggi, menyatakan bahwa kegiatan ekstrakurikuler adalah kegiatan kemahasiswaan yang meliputi: penalaran dan keilmuan, minat dan kegemaran, upaya perbaikan kesejahteraan mahasiswa dan bakti sosial bagi masyarakat. Kegiatan ekstrakurikuler jurusan sangat penting untuk diikuti oleh mahasiswa agar dapat mengembangkan kemampuan dan kreativitas, mengembangkan rasa dan tanggung jawab sosial, mengembangkan suasana rileks dan menyenangkan, serta mengembangkan kesiapan karier mahasiswa dimasa mendatang. Jika tidak mengikuti kegiatan maka mahasiswa akan tertinggal dari teman-temannya baik dari segi kognitif maupun ketertinggalan informasi dan manfaat program serta kurangnya bersosialisasi sehingga menimbulkan sifat individualisme dan malas membaur dengan lingkungan.

Jurusan Ilmu Sosial Politik juga mengadakan berbagai kegiatan ekstrakurikuler yang melibatkan mahasiswa yang bertujuan untuk memberikan pembelajaran, pengalaman, maupun informasi yang bermanfaat bagi mahasiswa. Beberapa kegiatan ekstrakurikuler yang diadakan oleh jurusan Ilmu Sosial Politik diantaranya yaitu kegiatan Kuliah Lapangan Kewarganegaraan (KLK) dan Bakti Sosial Ilmu Sosial Politik (Baksispol), kegiatan Yudisium Wisuda dan Penyambutan Mahasiswa 
Baru, serta kuliah umum untuk semua angkatan aktif jurusan ISP.

Menurut Bornby (dalam Putri 2017: 8) mengartikan partisipasi sebagai tindakan untuk mengambil bagian yaitu kegiatan atau pernyataan untuk mengambil bagian dari kegiatan dengan maksud memperoleh manfaat. Sedangkan menurut Sastropoerto (2011: 1), partisipasi adalah keterlibatan mental atau fikiran dan perasaan seseorang di dalam situasi kelompok yang mendorong untuk memberi sumbangan kepada kelompok dalam usaha mencapai tujuan tertentu serta turut bertanggung jawab terhadap usaha yang bersangkutan. Kesimpulannya bahwa partisipasi merupakan bentuk keikutsertaan seseorang atau sekelompok orang baik keterlibatan fisik maupun mental atau fikiran dalam suatu kegiatan yang diadakan dengan tujuan agar memperoleh suatu manfaat.

Data kehadiran mahasiswa ISP

UNP angkatan 2016-2019 dalam mengikuti kegiatan kuliah umum tanggal 6 November 2019, dari angkatan 2016 hanya 53 orang yang menghadiri kegiatan, dari angkatan 2017 sebanyak 120 orang, dari angkatan 2018 sebanyak 88 orang, dan dari angkatan 2019 sebanyak 90 orang. Jadi total mahasiswa ISP yang mengikuti kegiatan tersebut adalah 351 orang dengan persentase 68,96\% dan yang tidak mengikuti kegiatan tersebut sebanyak 158 orang dengan persentase $31,04 \%$.

Berdasarkan data tersebut, ditemukanlah masalah terkait kurangnya kesadaran mahasiswa untuk berpartisipasi dalam kegiatan ekstrakurikuler di jurusan Ilmu Sosial Politik. Setiap diadakan kegiatan, selalu ada mahasiswa yang tidak hadir dan tidak peduli dengan kegiatan ekstrakurikuler yang dibuat. Tujuan penulisan artikel ini yaitu untuk mengidentifikasi faktor-faktor penyebab mahasiswa ISP kurang berpartisipasi mengikuti kegiatan ekstrakurikuler yang diadakan oleh jurusan.

\section{METODE PENELITIAN}

Metode penelitian ini menggunakan metode kombinasi (mixed methods). Menurut Sugiyono (2017: 404) metode penelitian kombinasi merupakan suatu metode penelitian yang menggabungkan antara metode kuantitatif dengan metode kualitatif untuk digunakan secara besama-sama dalam suatu penelitian, sehingga diperoleh data yang lebih komprehesif, valid, reliabel, dan obyektif. Informan penelitian terdiri dari pembina HMJ ISP, pegawai Tata Usaha, dan mahasiswa jurusan Ilmu Sosial Politik sebanyak 19 orang, sedangkan responden yaitu mahasiswa ISP sebanyak 84 orang yang dijadikan sebagai sampel. Pengumpulan data dilakukan dengan wawancara dan penyebaran angket. Teknik analisis data kualitatif dilakukan dengan pengumpulan data, reduksi data, penyajian data dan verifikasi data, sedangkan teknik analisis data kuantitatif dengan memeriksa kelengkapan isi angket, mengolah data, menghitung persentase jawaban, serta menghitung Tingkat Capaian Responden (TCR). 
HASIL DAN PEMBAHASAN

\section{Partisipasi Mahasiswa dalam Kegiatan Ekstrakurikuler di Jurusan ISP}

Berdasarkan ditemukanlah masalah terkait kurangnya kesadaran mahasiswa untuk berpartisipasi dalam kegiatan ekstrakurikuler di jurusan Ilmu Sosial Politik. Setiap diadakan kegiatan, selalu ada mahasiswa yang tidak hadir dan tidak peduli dengan kegiatan ekstrakurikuler yang dibuat, padahal sudah diumumkan oleh pihak jurusan terkait kegiatan tersebut. Akibat kurangnya partisipasi mahasiswa dalam mengikuti kegiatan ekstrakurikuler, ketua jurusan mewajibkan kepada setiap mahasiswa untuk mengikuti kegiatan yang diadakan, namun masih ada juga mahasiswa yang tidak mengikuti kegiatan tersebut. Hal ini dapat dilihat dari partisipasi mahasiswa ISP dalam kegiatan ekstrakurikuler kuliah umum jurusan yang diadakan tanggal 6 November 2019. Berikut data kehadiran mahasiswa aktif ISP UNP angkatan 2016-2019 dalam mengikuti kegiatan kuliah umum:

Tabel 1. Partisipasi Mahasiswa ISP dalam Kegiatan Kuliah Umum

\begin{tabular}{|l|l|l|l|l|l|}
\hline $\begin{array}{l}\mathrm{N} \\
\mathrm{o}\end{array}$ & $\begin{array}{l}\text { Ang } \\
\text { kata } \\
\mathrm{n}\end{array}$ & $\begin{array}{l}\text { Jumlah } \\
\text { Mahas } \\
\text { iswa }\end{array}$ & $\begin{array}{l}\text { Keha } \\
\text { diran }\end{array}$ & $\begin{array}{l}\text { Ketidakh } \\
\text { adiran }\end{array}$ & $\begin{array}{l}\text { Perse } \\
\text { ntase } \\
\text { Keha } \\
\text { diran }\end{array}$ \\
\hline 1 & 2016 & 130 & 53 & 77 & $\begin{array}{l}40,76 \\
\%\end{array}$ \\
\hline 2 & 2017 & 152 & 120 & 32 & $\begin{array}{l}78,94 \\
\%\end{array}$ \\
\hline 3 & 2018 & 107 & 88 & 19 & $\begin{array}{l}82,24 \\
\%\end{array}$ \\
\hline 4 & 2019 & 120 & 90 & 30 & $\begin{array}{l}75 \% \\
.\end{array}$ \\
\hline $\begin{array}{l}\text { Juml } \\
\text { ah }\end{array}$ & 509 & 351 & 158 & $\begin{array}{l}68,96 \\
\%\end{array}$ \\
\hline
\end{tabular}

Sumber: Daftar hadir mahasiswa pada kuliah umum 6 November 2019
Berdasarkan data tersebut, dari angkatan 2016 hanya 53 orang yang menghadiri kegiatan, dari angkatan 2017 sebanyak 120 orang, dari angkatan 2018 sebanyak 88 orang, dan dari angkatan 2019 sebanyak 90 orang. Jadi total mahasiswa ISP yang mengikuti kegiatan tersebut adalah 351 orang dengan persentase 68,96\% dan yang tidak mengikuti kegiatan tersebut sebanyak 158 orang dengan persentase $31,04 \%$.

Partisipasi mahasiswa sangat diperlukan untuk menyukseskan kegiatan ekstrakurikuler jurusan yang diadakan. Adapun Menurut Y. Slamet (dalam Ni Wayan, 2016), penggolongan partisipasi berdasarkan pada cara keterlibatannya dapat digolongkan menjadi dua, yaitu; (1) Partisipasi langsung, yaitu terjadi jika seseorang melakukan kegiatan tertentu di dalam proses partisipasi, seperti contohnya mengambil peranan di dalam pertemuan atau rapat, ikut berdiskusi, menyumbangkan tenaganya dalam acara atau kegiatan yang dilaksanakan serta menghadiri kegiatan. (2) Partisipasi tidak langsung, yaitu terjadi jika seseorang melimpahkan wewenang hak partisipasinya, misalnya saat pengambilan keputusan dirinya diwakili oleh orang lain, tidak ikut serta menyumbangkan tenaga dalam kegiatan yang diadakan, namun ia menyumbangkan materi atau uang yang dimiliki.

Faktor-Faktor Penyebab Kurangnya Partisispasi Mahasiswa ISP dalam Kegiatan Ekstrakurikuler Jurusan

Kurangnya partisipasi mahasiswa ISP dalam kegiatan ekstrakurikuler jurusan disebabkan oleh berbagai faktor yang berbeda-beda setiap orangnya, oleh karena itu peneliti 
telah melakukan pengolahan data berdasarkan angket tentang faktorfaktor penyebab kurangnya partisipasi mahasiswa ISP dalam kegiatan ekstrakurikuler jurusan.

Berdasarkan temuan peneliti, dapat dideskripsikan bahwa faktorfaktor yang menyebabkan kurangnya partisipasi mahasiswa ISP dalam kegiatan ekstrakurikuler jurusan yaitu; faktor kesehatan, faktor ekonomi, faktor tugas kuliah, kendala izin orang tua, faktor malas, dan ajakan teman.

Faktor kesehatan sangat mempengaruhi partisipasi seseorang dalam suatu kegiatan, jika seseorang sakit maka tentunya dapat menghambat partisipasinya. Kebanyakan mahasiswa yang tidak mengikuti kegiatan ekstrakurikuler jurusan mengaku terkendala oleh masalah kesehatan sehingga tidak dapat mengikuti kegiatan yang diadakan. Menurut Slamet, keterlibatan seseorang dalam suatu kegiatan dipengaruhi oleh tiga faktor, yaitu kemauan, kemampuan, dan kesempatan. Yang dimaksud dengan kesempatan adalah situasi terbaik yang sedang seseorang hadapi dimana seseorang memiliki peluang yang sangat besar untuk mendapatkan hasil akhir terbaik pula. Hal ini berarti bahwa jika seseorang mengalami sakit maka ia tidak berkesempatan untuk berpartisipasi dalam kegiatan yang diadakan.

Faktor ekonomi juga menjadi kendala mahasiswa untuk berpartisipasi dalam kegiatan ekstrakurikuler jurusan, karena setiap diadakan kegiatan ekstrakurikuler jurusan seringkali harus membutuhkan biaya dan pengeluaran materi. Hal ini sesuai dengan pandangan Turner, yang menyatakan bahwa tingkat pendapatan akan memberi peluang yang besar bagi seseorang untuk ikut berpartisipasi. Kegiatan yang membutuhkan biaya misalnya kegiatan KLK dan Baksispol yang biasanya diadakan di luar Kota Padang yang membutuhkan biaya transportasi, perkemahan, dan sebagainya. Namun sebenarnya tidak semua kegiatan yang dibuat oleh jurusan untuk mahasiswa membutuhkan biaya pengeluaran dari mahasiswa seperti pada kegiatan kuliah umum yang hanya diadakan di gedung UNP.

Tugas kuliah sebagai salah satu alasan penghambat untuk berpartisipasi dalam kegiatan ekstrakurikuler jurusan, karena banyaknya tugas yang diberikan dan waktu yang sudah dekat sehingga mereka lebih memilih untuk mengerjakan tugas dan tidak menghadiri kegiatan. Hal tersebut sesuai dengan pernyataan Budiharjo \& Sujarto, bahwa waktu luang seseorang untuk terlibat dalam organisasi atau kegiatan juga dipengaruhi oleh jenis pekerjaannya. Dalam hal ini banyak mahasiswa yang telah disibukkan oleh tugas kuliah untuk dikerjakan sehingga membuat mereka terhalang untuk mengikuti kegiatan jurusan.

Kendala izin orang tua juga menjadi penyebab kurangnya partisipasi mahasiswa ISP karena terdapat mahasiswa ISP yang tidak diizinkan oleh orang tuanya untuk mengikuti kegiatan ekstrakurikuler jurusan dengan berbagai alasan. Hal ini berkaitan dengan faktor eksternal untuk dapat berpatisipasi menurut Mardikanto \& Soebiato (2013) yaitu kesempatan yang mendorong 
Volume 4 No. 22021

individu untuk ikut berpartisipasi dalam program, berupa pemberian akses. Oleh karena itu bagi mahasiswa yang tidak mendapat izin orang tua sebaiknya bisa menjelaskan dengan baik kepada orang tuanya tentang pentingnya kegiatan ekstrakurikuler jurusan yang diadakan dan dapat mengusahakan agar mendapat izin jika keadaan memungkinkan.

Terdapat mahasiswa ISP yang tidak mau berpartisipasi mengikuti kegiatan ekstrakurikuler karena rasa malas. Slamet (2003) menyatakan salah satu faktor pendukung partisipasi yaitu adanya kemauan untuk mengikuti kegiatan. Kemauan yaitu adanya sesuatu yang mendorong atau menumbuhkan minat dan sikap mereka untuk termotivasi berpartisipasi. Jika seseorang tidak memiliki kemauan atau adanya rasa malas maka tentunya ia tidak akan mau mengikuti kegiatan ekstrakurikuler yang diadakan oleh jurusan.

Ajakan teman untuk tidak mengikuti kegiatan, biasanya ajakan tersebut dilakukan oleh seseorang kepada teman atau yang memiliki kedekatan tertentu. Salah satu teori motif sosial yang dikemukakan oleh McClelland (1987) dalam Nurhadi (2017) yaitu Need of power adalah dorongan individu untuk mengendalikan dan mempengaruhi orang lain. Berdasarkan pernyataan tersebut sesuai dengan adanya mahasiswa ISP yang tidak mengikuti kegiatan ekstrakurikuler jurusan karena pengaruh temannya agar bersama-sama tidak mengikuti kegiatan.

Hasil penelitian lain yang dilakukan oleh Yama Hafiz (2018) tentang Partisipasi Mahasiswa Prodi
PPKn FIS UNP dalam Kegiatan HIMA, terdapat beberapa faktor penyebab rendahnya partisipasi mahasiswa PPKn pada kegiatan HIMA yaitu faktor internal dan eksternal dari mahasiswa. Faktor internalnya yaitu tidak adanya minat dan keinginan mahasiswa untuk berpartisipasi serta adanya mahasiswa yang setiap minggunya pulang kampung. Sedangkan faktor eksternalnya yaitu kegiatan HIMA yang tidak menarik serta banyaknya tugas kuliah sehingga tidak bisa berpartisipasi. Dalam hal ini terdapat beberapa faktor kesamaan penyebab mahasiswa tidak mengikuti kegiatan ekstrakurikuler yang diadakan oleh Jurusan ISP dengan kegiatan HIMA antara lain tidak adanya kemauan untuk mengikuti kegiatan serta banyaknya tugas kuliah.

\section{KESIMPULAN}

Berdasarkan hasil analisis data dan pembahasan, makan dapat ditarik simpulan yaitu terdapat enam faktor penyebab kurangnya partisipasi mahasiswa ISP dalam kegiatan ekstrakurikuler jurusan, adapun faktor-faktor tersebut yaitu; (a) faktor kesehatan dengan nilai Tingkat Capaian Responden 51,43\%, (b) faktor ekonomi dengan nilai Tingkat Capaian Responden 51,67\%, (c) faktor tugas kuliah dengan nilai Tingkat Capaian Responden 52,62\%, (d) faktor kendala izin orang tua dengan nilai Tingkat Capaian Responden 57,62\%, (e) faktor malas dengan nilai Tingkat Capaian Responden 62,86\%, (f) faktor ajakan teman untuk tidak mengikuti kegiatan dengan nilai Tingkat Capaian Responden 71,67\%.

Implikasi penulisan artikel ini terhadap penelitian lainnya adalah 
dapat membantu penelitian dalam memahami faktor-faktor penyebab kurangnya partisipasi mahasiswa dalam suatu kegiatan, sehingga adanya upaya yang dilakukan untuk meningkatkan partisipasi mahasiswa dalam kegiatan yang diadakan oleh Jurusan Ilmu Sosial Politik Fakultas Ilmu Sosial Universitas Negeri Padang.

\section{DAFTAR PUSTAKA}

Arvanny, Tika. Partisipasi Masyarakat dalam Pendidikan untuk Pendidikan Anak Usia Dini (Studi di TK Samudera Kelurahan Air Tawar Barat. Skripsi. Fakultas Ilmu Sosial. Universitas Negeri Padang.

Budiarjo, Mirriam. 2000. Partisipasi dan Partai Politik. Jakarta: Yayasan Obor Indonesia.

Budiharjo, E., \& Sujarto, E. 2009. Kota Berkelanjutan. Bandung: Penerbit Alumni.

Dahliyana, Asep. 2017. Penguatan Pendidikan Karakter melalui Kegiatan Ekstrakurikuler di Sekolah. Jurnal Sosioreligi, Vol.15, No.1, Maret 2017: hal 54-64.

Hafiz, Yama. 2018. Partisipasi Mahasiswa Prodi PPKN FIS UNP dalam Kegiatan Hima. Skripsi. Fakultas Ilmu Sosial. Universitas Negeri Padang.

Hamijoyo. 2009. Partisipasi dalam Pembangunan. Jakarta: Depdikbud RI.

Kepmendikbud RI No. 155/U/1998 tentang pedoman umum organisasi kemahasiswaan di perguruan tinggi.

Mardikanto, T., \& Soebiato, P. (2013). Pemberdayaan Masyarakat dalam
Perspektif Kebijakan Publik (2nd ed). Bandung: Alfabeta.

Nurhadi, A. (2017). Hubungan Antara Persepsi dan Keragaman Motif Sosial dengan Tingkat Partisipasi Masyarakat dalam Program CSR PT. Institut Pertanian Bogor.

Pradnyani, Ni Wayan. 2016. Analisis Faktor-Faktor yang mempengaruhi partisipasi mahasiswa fakultas ekonomi dalam mengikuti unit kegiatan mahasiswa (UKM) tahun 2014/2015. Jurnal program studi pendidikan ekonomi (JPPE). Vol.7 no.2 2016.

Putri, Rahma Tika. 2017. Partisipasi Pemuda dalam Pembangunan Nagari melalui Kesenian Sandiwara Pentas di Jorong Kuranji Kecamatan Guguak Kabupaten Lima Puluh Kota. Skripsi. Fakultas Ilmu Sosial. Universitas Negeri Padang.

Sastropoerto, S. 2011. Partisipasi, Komunikasi, Persuasi Dan Disiplin Dalam Pembangunan Nasional. Bandung: Alumni

Slamet, Y. (1994). Pembangunan Masyarakat Berwawasan Partisipasi. Surakarta: Sebelas Maret University Press.

Sugiyono. 2017. Metode Penelitian Kuantitatif, Kualitatif, dan Kombinasi (Mixed Methods). Bandung: Alfabeta 
P a g e | 156

Journal of Civic Education (ISSN: 2622-237X)

Volume 4 No. 22021 